\title{
CHEMISTRY OF VIRAL INFECTED CELLS*
}

\author{
W. Wilbur Ackermann and Philip C. Loh \\ Depariment of Epidemiology and Virus Laboratory, School of Public Health, \\ University of Michigan, A nn Arbor, Mich.
}

Upon the basis of limited data available ten years ago, a concept of viral infection became popular in which the cell was redirected after infection to the exclusive production of virus. These original data (Cohen, 1949) that concerned the quantitative accounting of the nucleoproteins during the infectious sequence, offered a direct line of investigation into the mechanism of this redirection and into the genesis of the cytopathic effect of the $T_{2}$ phage of Escherichia coli.

Since the early work of Cohen, there have been few attempts to establish an accounting of large molecules during infection with other viruses, particularly in well-defined systems of animal virsues. Such investigation is complicated by the fact that the yield of virus from infected animal cells is frequently low relative to the cell mass. What determines the yield is an interesting problem in itself, as well as how that viral production leads to cell destruction. At present there is no simple answer. It may be that the cytopathic effect terminates the viral production rather than the latter mediating the cytopathic effect.

However, a quantitative analysis of cells and fractions thereof infected with poliovirus was undertaken in our laboratory several years ago, and it was quickly established that, although the amount of virus formed was small, there were indeed massive increases in the total RNA and protein of the cell during the infectious process (Ackermann et al., 1959). These results have been confirmed elsewhere by microspectrophotometric analysis of single infected cells (G. Barski, personal communication; Tenebaum, 1957). They are further supported by the series of studies of the proteins and enzymes of cells infected with poliovirus (Matzelt $e l a l$., 1958). If a viral cytopathic effect requires a specific or locally restricted synthesis of an amount of material large relative to the cell mass, this is available in the poliovirus infection.

Since the report of these changes in cells induced by infection with the poliovirus, alterations of nucleic acid content of cells have been observed during the infectious sequence of several viral systems. Data concerning this point were collected in many laboratories and are not entirely comparable in all respects, but they have been summarized in TABLE 1. In these examples, the infected cells do not seem to be devoted to the exclusive production of materials that constitute what is usually regarded as the viral body.

\section{Alterations of Nucleic Acid Content Induced by Virus}

In each case where kinetic studies were undertaken to follow these changes, increases in nucleic acid were observed to occur progressively during the latent period. Usually the synthesis begins within an hour after the initiation of

* The work reported in this paper was supported in part by a grant from the National Science Foundation, Washington, D.C. 
infection and continues until the appearance of new infectious activity. The pattern (FIGURE 1) for vaccinia virus (Loh et al., 1959) conforms approximately with that described for infections with poliovirus (Ackermann et al. 1959), herpes virus (Newton and Stoker, 1958), pseudorabies (Kaplan and Ben-Porat, 1959), adenovirus (Ginsberg and Dixon, 1959a), and $T_{2}$ bacteriophage (Cohen, 1949).

A quantitative accounting of the various species of nucleic acids found in cells after infection with any particular virus is difficult to make, but it is presumed that part of the early formed nucleic acid is viral precursor. This is supported by the presence in infected $E$. coli of DNA containing hydroxymethylcytosine characteristic of the $T_{2}$ bacteriophage, by the presence of DNA in the cytoplasm of HeLa cells infected with vaccinia virus, together with the early sensitivity of that infectious sequence to inhibition by 5 -fluorodeoxyuridine (a specific inhibitor of DNA synthesis; Salzman, 1960), and by the infectious nature of RNA extracted early in the infection with tobacco mosaic virus.

TABLE 1

Viral-Induced Synthesis of Nucleic Acids in Animal Celis

\begin{tabular}{|c|c|c|c|c|}
\hline \multirow{2}{*}{ Virus } & \multirow{2}{*}{ Cell type } & \multicolumn{2}{|c|}{$\begin{array}{l}\text { Maximum per cent increase } \\
\text { per cell }\end{array}$} & \multirow{2}{*}{ Investigators } \\
\hline & & RNA & DNA & \\
\hline Poliovirus & $\mathrm{HeLa}$ & 100 & - & Ackermann et al. (1959) \\
\hline $\begin{array}{l}\text { Vaccinia } \\
\text { Pseudorabies } \\
\text { Herpes virus } \\
\text { Adenovirus-4 } \\
\text { Adenovirus-5 }\end{array}$ & $\begin{array}{l}\text { HeLa } \\
\text { Rabbit kidney } \\
\text { HeLa } \\
\text { HeLa } \\
\text { HeLa }\end{array}$ & $\frac{30-105}{-}$ & $\begin{array}{c}\overline{35} \\
100 \\
180 \\
\text { Severalfold }\end{array}$ & $\begin{array}{l}\text { Loh et al. (1959) } \\
\text { Kaplan and Ben-Porat (1959) } \\
\text { Newton and Stoker (1958) } \\
\text { Ginsberg and Dixon (1959a) } \\
\text { Boyer et al. }\end{array}$ \\
\hline
\end{tabular}

* Based on microspectrophotometric analysis of single cells.

However, in several systems where a net increase in nucleic acid could be observed (that is, with poliovirus, pseudorabies virus, adenovirus, vaccinia virus, and herpes virus), the quantities of the material formed after infection (TABLE 1) were found to be excessive in relation to the amount of virus ultimately produced. If the RNA formed in a single HeLa cell after infection with poliovirus were viral RNA, it would correspond to $10^{7}$ virus particles (Ackermann, 1958), while the DNA produced in one cell infected with herpes virus was estimated to be equivalent to $10^{6}$ virus particles (Newton and Stoker, 1958).

Further, in some instances a major part of the nucleic acid formed was not of the type found in the infecting agent, that is, RNA was produced in cells infected with a virus containing DNA (Ginsberg and Dixon, 1959b). The increases in DNA of cells infected with vaccinia virus revealed by cytochemical techniques (Alousi et al., 1960) are difficult to follow by direct chemical analysis because of the small magnitude of the increase. In contrast, the same methods readily show increases in RNA of 30 to 100 per cent of the normal values for the host-cell cytoplasm. This synthesis occurring after infection has been confirmed also by a study of the rate of incorporation of radioactive-labeled 


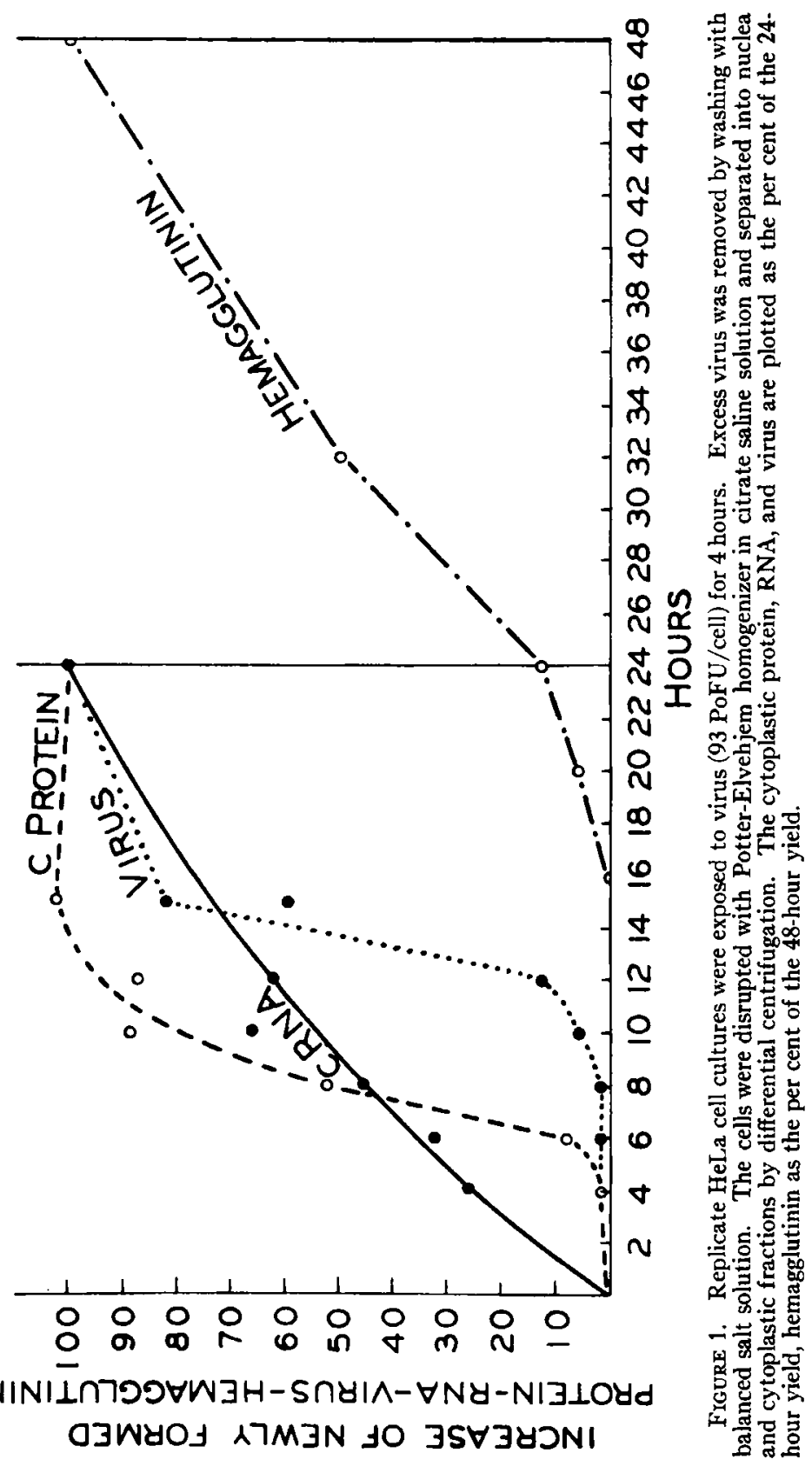


adenine into RNA (Joklik and Rodrick, 1959). A significant increase in the nuclear RNA of HeLa cells infected with type 5 adenovirus was also reported. However, the same cells show massive increases in DNA (Ginsberg and Dixon, 1959b). There is strongly suggestive evidence that this agent is also of the DNA type. By the use of tracer techniques, a considerable turnover of RNA was demonstrated in $E$. coli infected with $\mathrm{T}_{2}$ or $\mathrm{T}_{7}$ bacteriophage, but in these instances any net synthesis, if it occurs, is reported to be quite small relative to the DNA being synthesized (Volkin el al., 1958; Volkin and Astrachan, 1956).

In these infections that ultimately result in cell death, the net increases of nucleic acid were reported to be confined to either the nucleus or cytoplasm, but were not found in both. Within the limits of this small series, synthesis of RNA has been reported in cells infected with viruses of the DNA type, but a net synthesis of DNA has not been reported for infection with agents of the RNA type.

\section{Concept and Evidence for Functional Nonprecursal Viral RNA}

Clearly, materials are formed after infection that do not constitute what is generally defined as the virus, that is, the agent as it exists in the extracellular state. Could this material constitute part of the agent as it exists in its functional or reproductive form? The DNA viruses at least might resemble higher organisms to the extent that they possess in part of their life cycle-in the intracellular state-a specific RNA as well as DNA. While proteins characteristic of infection but antigenically unrelated to host or virus have not been investigated systematically, they are not unknown. Presumably, as with higher organisms, the specific RNA and protein would arise from the functioning of the specific DNA. These nucleic acids with the various structural proteins and enzymes, 25 of which are known for one system described by Flaks, could constitute a relatively complex intracellular organism, albeit not one organized within a single membrane, other than that contributed by the host cell. In this concept the isolable agent bears a formal relation to an inactive spore.

The problem then of defining the intracellular virus is one of deciding what specificities of the structure present were imposed by the infecting agent and their essentiality to its reproductive process. One aspect is approached by isolation and physical characterization of the materials, the second by segregation of the various activities through the use of specific inhibitors. In the latter case interpretations are more easily made where differential sensitivity of the activities are found.

Inhibition of the synthesis of DNA has not been found to inhibit the replication of RNA-containing viruses (Fairman, 1959; Tamm, 1960a and $b$ ), but the converse has been amply demonstrated. For example, 5,6-dichloro-1- $\beta$-Dribofuranosylbenzimidazole has been found to prevent the incorporation of adenine into RNA (Tamm, 1960a and $b$ ) and to inhibit the multiplication of vaccinia virus (Loh el al., 1959), adenovirus, as well as viruses of influenza and poliomyelitis. For some years it has been known that treatment of infected cells with RNase would prevent the multiplication of viruses of both the DNA and RNA types (Burnet et al., 1957; LeClerc, 1956; Tamm and Bablanian, $1960 b)$.

While each of these experiments contains some limitations and are subject to 
other interpretations, together they strongly suggest that either RNA synthesis or the exact conditions necessary for it are essential to the replication of several DNA viruses.

\section{Evidence for Viral-Induced Synthesis of Host-Cell Materials}

In addition to such specific RNA that functions in virus reproduction but acts not as a material precursor, there is in several infections a considerable cellular content formed presumably as a result of either continued or stimulated functioning of the host cell. This may arise as a mere incidental accompaniment that must occur when conditions are rendered suitable for viral synthesis. The cell architecture may not allow the conditioning for nucleoprotein synthesis of an area small enough for production of virus exclusively. There is considerable evidence that the activity of the cell is not devoted exclusively to virus production after infection, even with agents ultimately producing necrosis.

The major part of the RNA produced after infection of cells with poliovirus is similar in its base ratios to host-cell RNA and dissimilar to viral RNA (Ackermann et al., 1959; Ackermann, 1958). The increases in the glycolytic enzymes in the same system likewise clearly represent synthesis of cellular material during part of the infectious cycle of poliovirus (Matzelt et al., 1958). Continued cellular activity at even a higher level of organization is suggested by the report of nuclear division occurring without cellular division in HeLa cells after infection with pseudorabies (Kaplan and Ben-Porat, 1959). Furthermore, cellular division of parasynchronized cultures of HeLa cells was observed after infection with either Newcastle disease virus or influenza virus (Wheelock and Tamm, 1959).

Also meaningful to the present thesis are experiments that show that the massive synthesis of DNA observed in the infection with pseudorabies is not essential for multiplication of that virus, although it is a usual accompaniment of the infection. Heavily irradiated cells provide a suitable environment for multiplication of pseudorabies, but presumably the damaged host-cell elements cannot function and the incidental DNA synthesis that is the major activity in the normal infection does not occur (Kaplan and Ben-Porat, 1959). Also significant is the report that in cell suspensions poliovirus could be grown without net increases in RNA and protein. Unfortunately the cell injury imposed was not defined as in Kaplan's experiments (Salzman el al., 1959). The extent of synthesis of nonviral RNA in infections with either poliovirus or vaccinia virus is subject to certain variables that have not yet been suitably evaluated. The rate of development of the cytopathic effect may be an important factor and one responsive to the environmental conditions. Of course in any particular culture the accumulation of RNA is progressive only to a point, and cannot be demonstrated once cytopathic effects are so advanced that loss of cytoplasmic material has occurred (Rothstein and Manson, 1959; Maassab and Ackermann, 1959).

From a comparative viewpoint, the chemistry of the vaccinial infection that we will consider in some detail is of particular interest in that the agent contains DNA and develops at a cytoplasmic site in the cell. It should be possible to determine if the type of nucleic acid that undergoes hyperdevelopment depends 
upon the site of intracellular development, or is determined by the kind of nucleic acid found in the virus. The following data will show there is a considerable accumulation of RNA in the cytoplasm without a detectable net increase in the total cellular DNA. In this respect it superficially resembles the poliovirus that develops in the cytoplasm rather than the DNA-containing viruses that develop at a nuclear site.

\section{The Nucleic Acid Composition of Ordinary HeLa Cells Under Growing and Resting Conditions}

Since the generation time ( 20 hours) of HeLa cells is well within the period of infection studied, it is necessary to consider the changes in cellular constituents of the uninfected control cells under various conditions in comparison with changes induced by infection. Replicate cultures of HeLa cells kept under growing and resting conditions were analyzed over a 24-hour interval for their nucleic acid contents and number of cells. Resting conditions were produced by the use of maintenance medium (Scherer, 1953) and growth conditions with Eagle's medium (Eagle et al., 1957).

HeLa cells adapted to growth in either Eagle's basal medium supplemented with 20 per cent human serum or 60 per cent Hank's balanced salt solution with 40 per cent human serum were used. On the third day after implantation the cultures containing Eagle's medium were changed to fresh growth medium containing 20 per cent equine serum instead of human serum, and those grown in balanced salt solution were changed to 90 per cent Scherer's maintenance solution with 10 per cent equine serum. These cultures were reincubated and used on the fourth day following implantation. The cultures kept in Eagle's medium and the others maintained in Scherer's medium were called growing and resting cells respectively.

When cells kept under resting conditions were analyzed at the end of a 24hour incubation period at $37^{\circ} \mathrm{C}$., no changes in total RNA, DNA, or cell count were observed (FIGURE 2). However, when the cells were kept under growing conditions for 24 hours at $37^{\circ} \mathrm{C}$., increases in total RNA (100 per cent), DNA (20 per cent), and cell count ( 32 per cent) were observed. An alteration in the ratio of RNA-P to DNA-P was also observed for cells kept under growing conditions; however, such a change did not occur in cells kept under resting conditions.

\section{The Effect of Vaccinia Virus on HeLa Cell Cultures Under Resting and Growing Conditions}

When HeLa cells kept under growing or resting conditions were infected with vaccinia virus, certain alterations in cellular activity were observed that differed depending upon the conditions prevailing.

First, under growing conditions where the control cultures showed during a 24-hour interval increases in the number of cells (32 per cent), amount of nRNA-P (50 per cent) and nDNA-P (20 per cent), the infected cultures showed no significant changes (FIGURE 2) of this type after infection. However, the increases occurring in cRNA-P (50 per cent) and c-Protein (24 per cent) were upon infection further stimulated to 105 and 55 per cent respectively. 
Thus, under growing conditions that allow for net increase in the large molecules of both cell fractions, infection with vaccinia inhibits the nuclear activities and stimulates the cytoplasmic ones.

Second, under resting conditions that ordinarily cannot support net increases of these materials in either fraction, infection induces a net synthesis specifi-

\section{HR.}

O HOUR
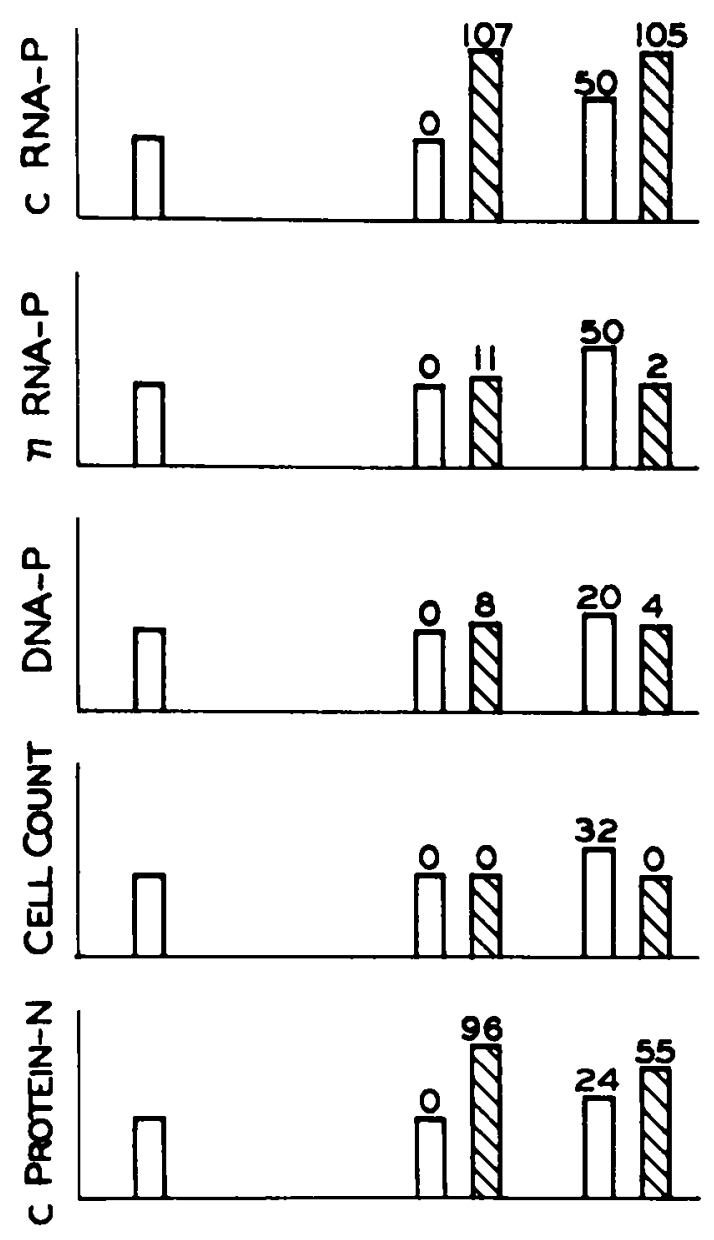

\section{$\square$ NORMAL $\square$ INFECTED}

FIGURE 2. Replicate cultures of resting and growing cells were prepared as described in the text. From control and infected cultures taken at 0 and 24 hours, fractions containing the nuclei and cytoplasm were obtained by homogenization and centrifugation. The amounts of DNA, RNA, and protein per fraction of one cell found at zero time were assigned the value of 100 . The per cent increases that occurred by 24 hours are indicated above the appropriate bars of the graph. 


\section{Ackermann \& Loh: Chemistry of Viral Infected Cells 1305}

cally in the cytoplasm (c-RNAP 107 per cent and c-Protein 96 per cent). The magnitude of these activities is quite comparable to those that occur under growing conditions, but seem more impressive when compared to either a 24or 0 -hour control resting culture.

\section{Kinetics of Net Synthesis of RNA, Protein, Virus, and Viral Hemagglutinin}

The pattern of increase of cytoplasmic RNA, protein, virus, and viral hemagglutinin was determined in replicate cultures of cells at various times in the interval from the initiation of infection to the 24 th hour. So that the characteristics of development of these materials that differ in absolute amount may be compared, the amount of each at the 24th hour was assigned the value of 100 and the amount at other times some proportion of 100 . In this form, data concerning the newly formed protein and RNA of the cytoplasm, viral infectivity, and viral hemagglutinin are plotted in FIGURE 1 . The increase of cytoplasmic RNA is detected as early as four hours after infection and can be represented by a shallow convex curve. It appears to accumulate at a decreasing rate during the latter part of the infectious period. However, increase in cytoplasmic protein is not detected until the fifth or sixth hour after infection, at which time it proceeds rapidly for the next several hours until, at about the 12th to 15th hour, it begins to level off.

Although the first increase in intracellular viral activity is not detected until 8 to 10 hours after infection, it proceeds rapidly for the next several hours and begins to reach maximum at about the 15 th hour. When the patterns of increase for both cytoplasmic RNA and protein are compared to that obtained for the virus, it should be noted that they precede the first appearance of intracellular viral activity by several hours. It is also of interest to note that $\mathbf{5 0}$ per cent of the protein and RNA are formed before the appearance of any viral activity. The evidence of stained preparations shows a detectable accumulation of cytoplasmic DNA eight hours before the appearance of infectious activity.

Unlike the findings with poliovirus, the increases of RNA and protein in the cytoplasm of cells infected with vaccinia virus do not closely parallel each other with respect to time during the infectious sequence. Further, subfractionation of the cell cytoplasm and subsequent analysis of the cells infected with poliovirus revealed increases in the protein and RNA of each fraction, although not to equal extent. The same procedure, when applied to the vaccinal infection, showed that the increase in the RNA content of the cytoplasm is accounted for largely by changes in the cell sap, while the increases in protein occur in the fraction containing the small particles.

The data in TABLE 2 were obtained from an analysis for RNA of fractions prepared from cells before infection and 17 and $\mathbf{4 1}$ hours after infection. Control cultures uninfected but of the same age were also treated in the same manner.

Cells were disrupted in citrate-saline containing versene with the PotterElveh jem homogenizer. The nuclear fraction was removed by centrifugation at $2000 \mathrm{~g}$ for $10 \mathrm{~min}$., while the small particles were sedimented by a force of $100,000 \mathrm{~g}$ applied for one hour. Presumably the cell sap so prepared contains 
the very low molecular weight RNA associated with amino acid activation, while the small particles contain the RNA of the microsomes.

It will be noted there was an increase of nearly 40 per cent in the total RNA per cell in both infected and uninfected cultures. This increase in RNA that occurred by 41 hours in the control culture was largely sedimentable with the nuclear fraction, while that of the infected cell was found largely in the cell sap fraction where the increase was 90 per cent greater than the value before infection.

In the same experiment, when protein determinations were made, the increases in protein occurred only in the infected culture and are accounted for largely by a 100 per cent increase in the small particles (TABLE 3).

TABLE 2

Ribonucleic Acid Content* of Fractions of Normal and Vaccinia-Infected Cells

\begin{tabular}{|c|c|c|c|c|c|c|c|c|}
\hline \multicolumn{4}{|c|}{ Infected } & \multirow{2}{*}{$\begin{array}{c}\text { Hours } \\
\text { after } \\
\text { infertion }\end{array}$} & \multicolumn{4}{|c|}{ Uninfected } \\
\hline Cell sap & $\begin{array}{c}\text { Small } \\
\text { particles }\end{array}$ & Nuclei & Total & & Cell sap & $\underset{\text { particles }}{\text { Small }}$ & Nuclei & Total \\
\hline $\begin{array}{l}10.49 \\
17.06 \\
20.05\end{array}$ & $\begin{array}{l}17.15 \\
22.31 \\
22.44\end{array}$ & $\begin{array}{r}11.17 \\
9.06 \\
10.27\end{array}$ & $\begin{array}{l}38.81 \\
48.43 \\
52.76\end{array}$ & $\begin{array}{r}0 \\
17 \\
41\end{array}$ & $\begin{array}{l}10.49 \\
13.44 \\
13.22\end{array}$ & $\begin{array}{l}17.15 \\
20.25 \\
20.00\end{array}$ & $\begin{array}{l}11.17 \\
14.32 \\
27.31\end{array}$ & $\begin{array}{l}38.81 \\
48.01 \\
60.53\end{array}$ \\
\hline
\end{tabular}

* Expressed as $\mu \mathrm{gm}$. of RNA phosphorus $\times 10^{-10}$ per fraction obtained from one cell.

TABLE 3

Protein Content* of Fractions of Normal and Vaccinia-Infected Celis

\begin{tabular}{|c|c|c|c|c|c|c|c|c|}
\hline \multicolumn{4}{|c|}{ Infected } & \multirow{2}{*}{$\begin{array}{c}\text { Hours } \\
\text { after } \\
\text { infection }\end{array}$} & \multicolumn{4}{|c|}{ Uninfected } \\
\hline Cell sap & $\begin{array}{c}\text { Small } \\
\text { particles }\end{array}$ & Nuclei & Total & & Cell sap & $\begin{array}{c}\text { Small } \\
\text { particles }\end{array}$ & Nuclei & Total \\
\hline $\begin{array}{l}111.3 \\
143.4 \\
127.9\end{array}$ & $\begin{array}{l}46.08 \\
75.60 \\
90.78\end{array}$ & $\begin{array}{l}79.38 \\
65.60 \\
71.42\end{array}$ & $\begin{array}{l}236.8 \\
284.6 \\
290.1\end{array}$ & $\begin{array}{r}0 \\
17 \\
40\end{array}$ & $\begin{array}{c}111.3 \\
122.8 \\
96.38\end{array}$ & $\begin{array}{l}46.08 \\
58.00 \\
53.30\end{array}$ & $\begin{array}{l}79.38 \\
63.84 \\
94.98\end{array}$ & $\begin{array}{l}236.8 \\
244.6 \\
244.7\end{array}$ \\
\hline
\end{tabular}

* Expressed as $\mu \mathrm{gm} . \times 10^{-\theta}$ of protein per fraction obtained from a single cell.

It is conceivable that the increases in the small molecular weight RNA induced by infection have a function in the synthesis of the protein found subsequently in the small particles.

The data of TABLES 1 and 3 were taken from a single experiment. It is of particular interest to note that, while the trend of such experiments with vaccinia virus is reproducible, the quantitative aspects are not. The inhibition of increase of RNA and protein in the nucleus is consistent, but the magnitude of the incremental protein and RNA of the cytoplasm is quite variable from one experiment to another. I.t may be concluded from the data, as with those cited previously for other virus systems, that this hyperdevelopment of part of the cell is more incidental to than essential for virus production. As with the carcinogenic viruses, there is some suggestion that an inverse relation may exist. Environmental conditions in tissue culture that seem to favor production of polyoma virus also favor a marked necrotic type of cytopathic effect. 


\section{Ackermann \& Loh: Chemistry of Viral Infected Cells}

The environmental factors important to the phenomenon have not as yet been elucidated clearly. The findings suggest that the virus interferes with an important controlling mechanism in the cell that has not been encountered yet in other connections.

\section{References}

Ackermann, W. W. 1958. Cellular aspects of the cell-virus relationship. Bacteriol. Rev. 22: 223.

AckermanN, W. W., P. C. Loh \& F. E. Payne. 1959. Studies of the biosynthesis of protein and ribonucleic acid in HeLa cells infected with poliovirus. Virology. 7: 172.

Alousi, M., H. Kurtz \& W. W. Ackermann. 1960. Morphology of the vaccinial infection in tissue culture. Federation Proc. 19: 403.

Burnet, F. M., P. E. Lind \& B. Perry. 1957. The action of ribonuclease on the multiplication of influenza viruses in the deembryonated egg. Australian J. Exptl. Biol. Med. Sci. 35: 517.

Corien, S. S. 1949. Growth requirements of bacterial viruses. Bacteriol. Rev. 13: 1.

Eagle, H., U. L. Oyama, M. Levy \& A. Freeman. 1957. Myo-inositol as an essential growth factor for normal and malignant human cells in tissue culture. J. Biol. Chem. 226: 191 .

Fairman, M. 1959. The effects of 5-fluorouracil on Rous sarcoma infection in vitro. J. Gen. Microbiol. 20: ii.

Ginsberg, H. S. \& M. K. Dixon. 1959a. Deoxyribonucleic acid (DNA) and protein alterations in HeLa cells infected with type 4 adenovirus. J. Exptl. Med. 109: 407.

Ginsberg, H. S. \& M. K. Dixon. 1959b. Alterations of nucleic acids in adenovirus infected Hela cells. Federation Proc. 18: 569.

JoKLIK, W. K. \& J. MCN. RODRICK. 1959. Biochemical studies on vaccinia virus in cultured cells. I. Incorporation of adenine-8- $\mathrm{C}^{\mathbf{1}}$ into normal and infected cells. Virology. 9: 396.

Kaplan, A. S. \& T. BEn-Porat. 1959. The effect of pseudorabies virus on the nucleic acid metabolism and on the nuclei of rabbit kidney cells. Virology. 8: 352 .

LECLERC, J. 1956. Action of ribonuclease on the multiplication of the influenza virus. Nature. 177: 578.

Loh, P. C., F. E. Payne, M. Nakamura \& W. W. Ackermann. 1959. Synthesis of RNA in HeLa cells infected with vaccinia virus. Federation Proc. 18: 581.

MaAssab, H. F \& W. W. ACKermann. 1959. Nucleic acid metabolism of virus-infected HeLa cells. Ann. N. Y. Acad. Sci. 81: 29.

Matzelt, D., J. Homman \& H. LenNette. 1958. Das Verhalten glykolytisher Enzymaktivitaten in Gewebekulturen vor und nach Beimpfung mit Virus. II. Messungen an Gewebekulturen, die mit Poliomyelitisvirus Type I, infiziert wurden im Vergleich zwei normalen Gewebekulturen. Biochem. Z. 330: 260.

Newton, A. \& M. C. Stoker. 1958. Changes in the nucleic acid content of Hela cells infected with herpes virus. Virology. 3: 549.

Rothstern, E. L. \& I. A. Manson. 1959. Phosphorus incorporation into high molecular weight RNA of poliovirus-infected HeLa cells. Virology. 9: 141.

Salzman, N. P., R. Z. Lockart \& E. O. Sebring. 1959. Alterations in Hela cell metabolism resulting from poliovirus infection. Virology. 9: 244.

Salzman, N. P. 1960. The rate of formation of vaccinia deoxyribonucleic acid and vaccinia virus. Virology. 10: 150.

SCHERER, W. F. 1953. The utilization of a pure strain of mammalian cells (Earle) for the cultivation of viruses in vifro. I. Multiplication of pseudorabies and herpes simplex viruses. Am. J. Pathol. 29: 113.

TAmm, I., M. M. Nemes \& S. Osterhaut. 1960a. On the role of RNA in animal virus synthesis: Studies with benzimidazole. J. Exptl. Med. 111: 339.

Tamm, I. \& R. Bablanian. 1960b. On the role of ribonucleic acid in animal virus synthesis. II. Studies with ribonuclease. J. Exptl. Med. 111: 351.

TENENBAUM, E. 1957. Changes in cellular nucleic acids during infection with poliomyelitis virus as studied by fluorescent microscopy. Nature. 160: 1044 .

Volkin, E. \& L. Astrachan. 1956. Phosphorus incorporation in E. coli ribonucleic acid aiter infection with bacteriophage $T_{2}$. Virology. 2: 149.

Volkin, E., L. Astrachan \& J. L. Countryman. 1958. Metabolism of RNA phosphorus in $E$. coli infected with bacteriophage $T_{7}$. Virology. 6: 545 .

WheElock, E. F. \& I. TAMm. 1959. Mitosis and division in HeLa cells infected with influenza and Newcastle disease virus. Virology. 8: 532. 